\title{
Um retrato de valor inestimável
}

Betty Mindlin

O NDAS DE esperança nos inundam com este livro de João Capiberibe, uma autobiografia inacabada. Esta começa quando o menino de sete anos deixa pela primeira vez a distante floresta de Marajó, ao embarcar para Macapá; termina com a saída para o exílio no Canadá, logo depois do golpe militar no Chile, em 1973. Há apenas alguns comentários sobre episódios posteriores à volta ao país em 1979, graças à Lei da Anistia. Emerge das páginas um dos melhores brasileiros da atualidade, e uma das mais solares brasileiras, sua mulher Janete.

Seguimos com o coração aos pulos um percurso heroico. Os dois são presos pela repressão em 1970, com pouco mais de 20 anos de idade. Janete, grávida de oito meses, consegue, após passar muito mal, dar à luz a filha Artionka e ser solta, enquanto João é levado de uma cadeia a outra por quase um ano, submetido a todos os horrores da época. É a fibra de ambos, mantida uma chama contínua de otimismo e força de vontade, que os faz vencer, com muitos apoios e acasos, "fortuna e virtù": dá certo a sua fuga romanesca da prisão, inimaginável nesses tempos sombrios, sonhada desde o primeiro dia! Seguem-se outras, tão ou mais terríveis, no trajeto para Santarém, Manaus, Porto Velho, Guajará-Mirim, Guayaramirim, Cochabamba. De lá, a passagem clandestina, sem documentos, dinheiro ou pertences, com a menina de colo, para La Paz e Desaguadero, em uma Bolívia esfuziante e revolucionária, que sofre um golpe poucas horas depois da chegada dos três. Escapam da morte por um fio, em direção ao Peru e ao Chile, onde finalmente se instalam e têm por um ano e meio a experiência de viver em um assentamento rural, uma utopia se não fosse verdadeira. Estudam, plantam, têm gêmeos gerados durante a primeira fuga. Novo golpe, o de 11 de setembro de 1973; após lances de risco e pavor, obtêm por fim o visto de imigrantes no Canadá.

Sofrimentos inauditos e salvações milagrosas são o signo da vida do casal. O livro não se dedica ao retorno ao Brasil, quando João elegeu-se prefeito de Macapá em 1988, governador do estado em 1994 por dois mandatos, e senador em 2002, mandato interrompido pelas garras da prepotência política e econômica, ainda mais nítidas no Amapá que nas raízes maranhenses, e que resultaram em sua cassação. Em 2010, foi reeleito para o Senado. Janete foi vereadora de Macapá, deputada estadual do Amapá por três mandatos, foi eleita deputada federal em 2002, cassada em 2005, como o marido, e novamente eleita deputada federal em 2006 e 2010. E hoje, 2013, o menino nascido no Chile, Camilo, gêmeo de Luciana, é o governador do Amapá. A floresta é devastada no Brasil, os índios enfrentam a mais séria ameaça de todos os tempos às demarcações, mas no Amapá as diretrizes são outras - embora nem sempre vitoriosas.

Vários ângulos ressaltam do longo depoimento de João e nos fazem pensar sobre a alternância de opressão e liberdade, ao longo de uma luta sem trégua. Talvez o primeiro seja o temperamento bem-humorado, a confiança no suces- 
so, a facilidade de diálogo e o afeto que permeiam todos os contatos humanos dos dois. Em cada canto, na cadeia, nos barcos, na vizinhança, nos paus-de-arara, eles fazem grandes amigos e aliados. Pode-se imaginar que esse caráter luminoso se deva, por um lado, à origem na floresta, em pequenas comunidades, isoladas, mas onde todos se conhecem e valorizam as relações pessoais; e por outro, à força da militância organizada, e de uma visão estudiosa de como chegar à justiça, à igualdade social, à preservação ambiental e aos direitos humanos.

Um outro ângulo é o retrato da ditadura brasileira, comparando-a à situação dos vizinhos, com pinceladas sobre os acontecimentos na Bolívia, no Peru, no Chile, e sobre o triste papel dos Estados Unidos. São evocados os grandes companheiros de resistência, os mais humildes, os intelectuais, a família. Um retrato de valor inestimável para os jovens, os estudantes, as escolas, todos os que vieram depois e hoje buscam construir e mudar o mundo como o João e a Janete de então, que jamais perderam o norte anterior; ao contrário, tornaram concretos seus anseios.

Central, ainda, é a recriação do que são as prisões brasileiras, certamente mais trágicas durante a ditadura, mas ainda agora com muitos dos mesmos traços. A descrição emocionada e viva de Capiberibe, transportando-nos para dentro das grades como se fosse o presente e se fôssemos nós os protagonistas, insere Florestas do meu exílio em uma vasta tradição, da qual são paradigmáticos Memórias do cárcere, de Graciliano Ramos, ou Ressurreição, de Liev Tolstói, a par de tão numerosas obras e filmes recentes, aqui ou em outros países. Podemos ver a escrita de Capiberibe sobre o

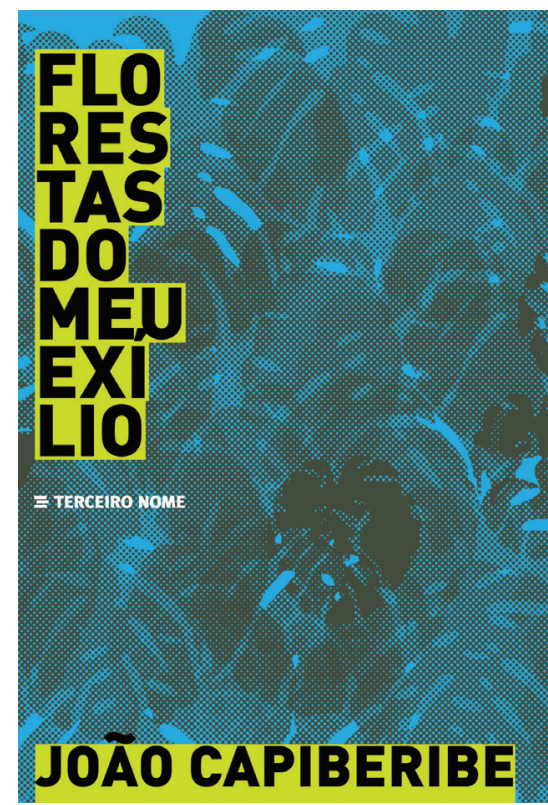

CAPIBERIBE, J. Florestas do men exilio. São Paulo: Terceiro Nome, 2013. 368p.

que viveu na pele como um libelo contra o sistema prisional, que é tão urgente substituir por alguma outra instituição que faça valer a lei e reafirmar valores de convivência.

Que esta biografia parece um romance de ficção, ocorre a quem vir os dois personagens, João e Janete, juntos, unidos, com o vigor antigo, de aparência moça, conduzindo uma família inventiva e amorosa. João lembra como, feminista precoce, realizava as mesmas tarefas que a mulher, de lavar, cozinhar, trocar fraldas, enquanto ao mesmo tempo era um camponês plantando o que comiam e construindo a própria casa, com o hábito do trabalho manual e a habilidade com consertos e a matéria, mais que útil na precariedade das mudanças.

Para além da leitura, fica o desejo de acompanhar no terreno a continuidade 


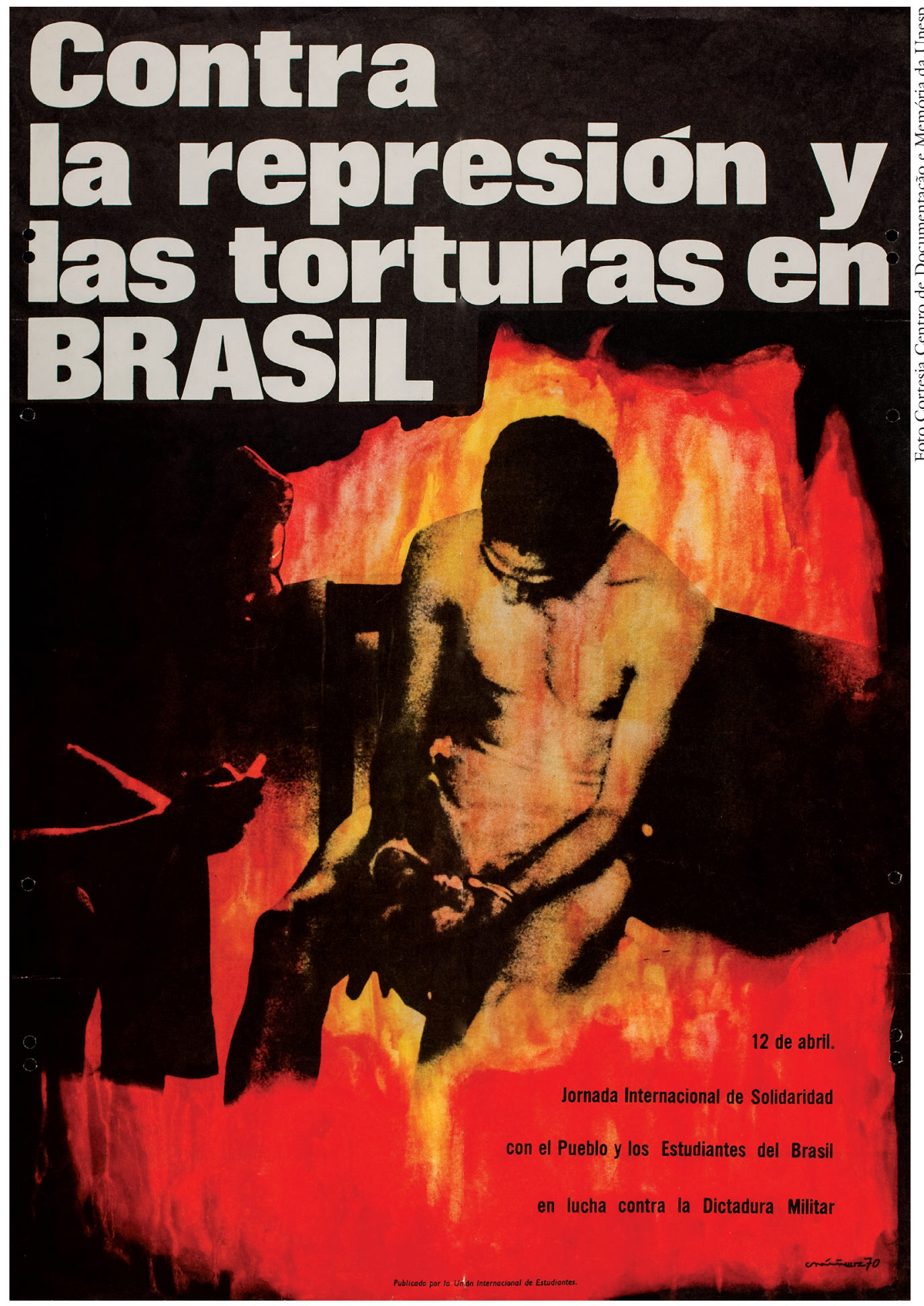

Cartaz da Unión Internacional de Estudiantes se solidariza com a luta contra a ditadura. 
desses destinos, aos quais se une agora o do governo do Amapá pelo filho de ambos, Camilo Capiberibe. Que floresta e índios tenham por lá as mesmas glórias dessas vidas bem-sucedidas.

Betty Mindlin é antropóloga, autora, em conjunto com narradores indígenas, de Moqueca de maridos (Paz e Terra, 3.ed. no prelo ) e outros livros.

@ - arampia.mindlin@gmail.com

II Instituto de Antropologia e Meio Ambiente, Iamá. São Paulo/SP, Brasil. 